\title{
Book Review: Big History and the Future of Humanity
}

\author{
Diego Chialva * \\ Service de Mecanique et Gravitation, Université de Mons, Mons, Belgium
}

Keywords: cosmology, big history, book review, physics, multidisciplinary approach

\section{A book review on \\ Big History and the Future of Humanity}

by Fred Spier, edited by Wiley-Blackwell, 2015, 288 pages. ISBN: 978-1-118-88172-9

The book "Big History and The Future of Humanity" [1] deals with the so-called big history, an approach that places the standard historical analysis in the wider framework of the entire evolution of the universe. It aims at uncovering patterns that could not be appreciated "if one were to examine only smaller portions of our past," page 30.

The amount of knowledge and the diversity of the disciplines necessary to compose the wishedfor big history picture (physics, chemistry, biology, geology, history, and many more) impose a multidisciplinary approach. However, the analysis in the book is undertaken by a single author. Evidently, no single author can master the different disciplines at the required level. This makes the book immediately questionable from the viewpoint of a robust big history approach itself. However, this could still be somewhat compensated if the analysis delivered the promised new insights. Let us discuss this.

The contrast between the required strongly multidisciplinary approach and its single-author nature makes the book appear rather amateurish at first, but unfortunately the situation is worse. The book contains several serious misconceptions about physical phenomena and their theoretical interpretations. Some of these errors are remarkably naive (for instance, on page 82 the author defines the neutrinos, I quote, "little neutrons," oblivious of a century of study in fundamental interactions), many are fundamental (for example concerning the radiation era, the role of "empty space" within atoms, and so on).

Other mistakes directly affect the pillars at the basis of the author's analysis. The author indeed claims a single principle underlying all evolution in the universe (physical, chemical, biological, cultural, and so on): the growth of complexity determined by energy flow and Goldilocks conditions. Unfortunately, his presentation of the three basic concepts (complexity, energy and Goldilocks conditions), plus a fourth extremely relevant one (entropy) is either incomplete, problematic or incorrect.

A most evident case is energy. Let us recall that energy is a concept central to physics since about a couple of centuries. It is defined both conceptually and operationally. Rather unexpectedly -and remarkably- the author writes (Chapter 2) that he could not find a complete and clear definition of energy in any physics book. He proceeds by giving a definition (I quote it: "anything that can change matter") that is absolutely empty and lumps together the concepts of interactions, physical transformations, matter and many others (but it is difficult to judge how much the author is aware of these things). All the modern concept of energy is omitted, including aspects, like its equivalence to mass, nowadays known to the educated general public at least by hearsay.

Complexity and Goldilocks conditions present instead quite a lack of definition. Concerning complexity, lacking a truly universal consensus, the author should at least clearly indicate what definition he adopts. He seems to do so when in Chapter 2 he claims to define complexity via 
"an inventory list of its mayor characteristics" (I quote), but this list is not organically presented and not all of its elements are clearly indicated. The authors analysis requires defining a measure of complexity, which would be indeed a good definition of it, but the power density he proposes (following Chaisson) is very problematic, as the authors himself often admits. In fact one wonders how he can calculate power if he claims a clear definition of energy is not available in physics.

As for Goldilocks conditions, while they should somehow be conditions at which a given "complexity" can exist, their nature largely varies and no clear concrete quantitative operational definition is provided. For example, in some parts of the book Goldilocks conditions are presented as "circumstances facilitating the stabilization of irregular matter and energy flows" (page 143,171), but elsewhere it does not appear what are their concrete features or even just added value (for example, on page 89 one reads that Galaxies formed thanks to certain Goldilocks conditions, but "since then, Galaxies have continued to exist" with different conditions-without specifying the features of the Goldilocks ones).

The misuse of the concept of entropy is another very relevant problem. In fact, its meaning in the book ranges from a quantity entering the Second Law of Thermodynamics (superficially discussed on page 53), to the, literally, "contamination (entropy) in the water supply," page 267, also 236. It is quite remarkable, in this respect, that the author proudly announces that "the Second Law of Thermodynamics plays a major role in the theoretical approach advocated here."

The lack consistency in the analysis is evident also in other fundamental aspects. For example, the author finds the pinnacle of the claimed overall increase of complexity of the

\section{REFERENCES}

1. Spier, F. Big History and the Future of Humanity, 2nd ed. Oxford, UK: Wiley-Blackwell (2015). 288 p.

Conflict of Interest Statement: The author declares that the research was conducted in the absence of any commercial or financial relationships that could be construed as a potential conflict of interest. universe in the human phenomenon, capable to create forms of artificial complexity. However, it is difficult to argue that the much lower complexity of agricultural landscapes and human settlements, compared to the much higher complexity of the natural landscapes they replaced, supports the author's conclusion about an increase in the overall universe complexity (in fact the author seems to acknowledge the problem and argue for a sort of "increased productivity [.... from a human perspective," page 237, 220, in substitution of the neutral concept of complexity).

Overall, in particular when considering the physical evolution of the universe, the author appears to bend the data to his hypothesis. He also frequently does not give evidence for his statements, adopting expressions like "I believe," "I think."

Finally, while big history could have its merits as a holistic attempt to study of the universe opposed to more reductionist approaches, does the book fulfills its claimed aim of being an introduction and justification of it, showing "general patterns that would remain obscured if one were to examine only smaller portions of our past"?

The answer unfortunately is not positive: the scientific mistakes concerning concepts at the basis of the general pattern claimed by the author, make his analysis weak and generally this does not add to the results obtained by the "small histories" provided by the specific scientific, social, historical investigations.

\section{ACKNOWLEDGMENTS}

The work was supported by the Belgian National Fond de la Recherche Scientifique F.R.S.-F.N.R.S. with a contract chargé de recherche and the University of Mons.
Copyright (C) 2015 Chialva. This is an open-access article distributed under the terms of the Creative Commons Attribution License (CC BY). The use, distribution or reproduction in other forums is permitted, provided the original author(s) or licensor are credited and that the original publication in this journal is cited, in accordance with accepted academic practice. No use, distribution or reproduction is permitted which does not comply with these terms. 